\title{
Studies on the Disposition of Fadrozole Hydrochloride (CGS 16949A) (II): Absorption, Distribution, Metabolism and Excretion after Repeated Oral Administration to Rats
}

\author{
Satoru Yamagami, Eiko Kawasaki and Asao Egawa \\ Pharmacokinetic Research Laboratory, Ciba-Geigy Japan Limited, \\ 10-66 Miyuki-cho, Takarazuka-shi 665, Japan \\ Yoshio Esumi, Katsuyuki Hori, Masao Ishizaki, \\ Takako Honda and Ryoko Nemoto \\ Tokai Research Laboratories, Daiichi Pure Chemicals Co., Ltd., \\ 2117 Muramatsu, Tokai-mura, Naka-gun, Ibaraki-ken 319-11, Japan
}

Key words ; Fadrozole hydrochloride (CGS 16949A), Rat, Repeated administration, Absorption, Distribution, Metabolism, Excretion

\begin{abstract}
Summary
The absorption, distribution, metabolism, and excretion of ${ }^{14} \mathrm{C}$-fadrozole hydorochloride $\left({ }^{14} \mathrm{C}-\mathrm{CGS} 16949 \mathrm{~A}\right)$ were investigated during and after repeated oral administration to nonfasted female rats at a daily dose of $1 \mathrm{mg} / \mathrm{kg}$ for 21 days.

1. The levels of radioactivity in the plasma (24hr after daily dosing) reached a steady state after the 15th dosing and was 3.1times higher than that found after the 1st dosing. The peak concentration $(\mathrm{C} \max$ ) and the half-lives after 21st dosing were $477 \mathrm{ng}$ eq. of CGS 16949 (the base of CGS $16949 \mathrm{~A}$ ) $/ \mathrm{ml}$ and $10 \mathrm{hr}$ from $4 \mathrm{hr}$ to $24 \mathrm{hr}$ and $65 \mathrm{hr}$ from $48 \mathrm{hr}$ to $168 \mathrm{hr}$.

2. The excretion ratio of radioactivity in the urine and feces reached a steady state after the 4th dosing and the excretion ratio after the 21st dosing was similar to that after single dosing.

3. The levels of radioactivity in the tissues after the 7th dosing increased in comparison with those after single dosing and the radioactivity levels after the 14th dosing were similar to those after the 7 th dosing. The radioactivity in aorta after the 21st dosing was 8.9times higher than that after single dosing.

4. The relative amount of unchanged CGS 16949 in the plasma after the 21 st dosing decreased and that of the metabolite with hydantoin type structure, MP2 increased, compared with those after single dosing. There were no significant differences between the concentration of CGS 16949 after single and the 21st dosing.

5. The relative amount of CGS 16949 and its metabolites in the urine for 24hours after 21st dosing was not significantly different from that after single dosing.
\end{abstract}




\section{INTRODUCTION}

Fadrozole hydrochloride (CGS 16949A), 4-(5, 6, 7, 8-tetrahydroimidazo [1, 5-a]-pyridin-5 -yl) benzonitrile monohydrochloride, is a potent, selective and non-steroidal competitive inhibitor of aromatase ${ }^{1)}$, whose absorption, distribution, metabolism and excretion have been reported after a single oral administration of ${ }^{14} \mathrm{C}-\mathrm{CGS} 16949 \mathrm{~A}$ to female rats ${ }^{2}$.

Since CGS 16949A is administered repeatedly in the pharmacological studies and clinical trials, the absorption, distribution, metabolism and excretion of ${ }^{14} \mathrm{C}$-labelled CGS $16949 \mathrm{~A}$ were investigated after repeated oral administration to non-fasted female rats in this study, and the steady state level of radioactivity in plasma, tissues and excreta and the accumulation of radioactivity were examined.

\section{MATERIALS AND METHODS}

\section{Labelled Compound}

${ }^{14} \mathrm{C}-\mathrm{CGS}$ 16949A was synthesized by Daiichi Pure Chemicals Co., Ltd. The labelled position of ${ }^{14} \mathrm{C}$-CGS $16949 \mathrm{~A}$ is shown in Fig. 1. The specific radioactivity of the labelled compound was $3.86 \mathrm{MBq} / \mathrm{mg}$, and the radiochemical purity of the labelled compound was more than $97 \%$ during the experimental period; this was determined by thin-layer chromatography as described in a preceding paper ${ }^{2}$.

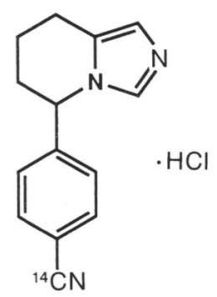

Fig. 1 Chemical structure and labelled position of ${ }^{14} \mathrm{C}-\mathrm{CGS} 16949 \mathrm{~A}$

\section{Experimental Animals}

Sprague-Dawley strain SPF female rats (obtained from Charles River Japan, Inc.) at 7 weeks of age, weighing about $200 \mathrm{~g}$ were used in this study.

Rats were acclimatized as described in the preceding paper ${ }^{2)}$ and were assigned to each test group. Three animals were assigned to each test group and one animal per group was used for whole body autoradiography.

\section{Dose Level and Administration of the Test Article}

${ }^{14} \mathrm{C}$-CGS 16949A mixed with unlabelled CGS 16949A was dissolved in distilled water and used to prepare a $0.5 \mathrm{mg} / \mathrm{m} l$ dosing solution. The dosing solution of $2 \mathrm{~m} l / \mathrm{kg}$ was administered orally to rats by gavage once daily at a fixed time for 21days. The radioactivity dosed to rats was $1.93 \mathrm{MBq} / \mathrm{kg}$. 


\section{Measurement of Radioactivity}

Radioactivity in each test sample was counted by a liquid scintillation counter (LSC903 or LSC-3600, ALOKA) for $2 \mathrm{~min}$. The counting efficiency was corrected by the Channel Ratio method using external standard sources. Concentrations of radioactivity in plasma or tissues were expressed as ng eq. of CGS 16949 (the base of CGS $16949 \mathrm{~A}) / \mathrm{m} l$ or $\mathrm{g}$.

\section{Determination of Radioactivity Concentration in Plasma}

Blood was withdrawn from the caudal vein of the animals $24 \mathrm{hr}$ after each administration and 5, 15 and $30 \mathrm{~min}, 1,2,4,6,8,12,24,48,72,96,120,144$ and $168 \mathrm{hr}$ after the $21 \mathrm{st}$ administration and im mediately centrifuged $\left(4^{\circ} \mathrm{C}, 1800 \times \mathrm{g}, 15 \mathrm{~min}\right)$ to obtain plasma. The radioactivity concentration in the plasma was counted as described in the preceding report ${ }^{2}$.

\section{Determination of Excretion of Radioactivity in Urine and Feces}

Urine and feces were collected for 24hours after each administration and for every 24 hours up to $168 \mathrm{hr}$ after the $21 \mathrm{st}$ administration. The radioactivity in the urine and feces was counted as described in the preceding report ${ }^{2}$. The residual radioactivity in carcass at $168 \mathrm{hr}$ after the $21 \mathrm{st}$ doses was also measured as described in the preceding report ${ }^{2}$.

\section{Whole Body Autoradiography}

Rats were sacrificed by ether inhalation 8, 24 and $168 \mathrm{hr}$ after the 21 st administration. Whole body autoradiograms were prepared as described in the preceding report ${ }^{2}$.

\section{Determination of Radioactivity Concentration in Tissue}

Rats were exsanguinated from the abdominal aorta under ether anesthesia $24 \mathrm{hr}$ after the 7 th and 14th administration and 2, 8, 24, 72, 168, 336 and 672hr after the 21st administration. The tissues were excised and the concentrations of radioactivity in the plasma, blood and tissues counted as described in the preceding report ${ }^{2}$.

\section{Analysis of Metabolites}

1) Samples for Analysis

Plasma samples (2, 8 and $24 \mathrm{hr}$ after the 21st administration), urinary and fecal samples (0-24hr after the 21st administration), liver and kidney samples $(2,8$ and $24 \mathrm{hr}$ after the 21st administration) were used for the analysis of metabolites.

\section{2) Analytical Methods}

Each sample was pretreated by solid-phase extraction and each extract was evaporated into dryness. The residue was dissolved with a small amount of mobile phase and the solution was applied to HPLC system described in the previous report ${ }^{2}$.

\section{Calculation of Pharmacokinetic Parameters}

The values of pharmacokinetic parameters were calculated from the individual plasma concentration-time curve of radioactivity in three animals. The values of area under the 
concentration-time curve (AUC) were calculated by the trapezoidal method. Apparent half-life values $\left(\mathrm{T}_{1 / 2}\right)$ were estimated using the least square method of actual data.

Student t-test with two-tailed probabilities was used for the analysis of the significance of difference.

\section{RESULTS}

\section{Radioactivity Concentration in Plasma}

The radioactivity concentrations in the plasma (equivalent to CGS 16949) during repeated dosing are shown in Fig. 2. The radioactivity concentration in the plasma at $24 \mathrm{hr}$ after daily dosing reached a steady state after the 15 th dosing and was 3.1 times higher than that after the 1st dosing.

The radioactivity concentration in the plasma after the 21 st dosing is shown in Fig. 3 compared with the level after single dosing ${ }^{2}$. The radioactivity concentration in the plasma reached a peak $\left(\mathrm{C}_{\max }\right.$ ) of $477 \mathrm{ng}$ eq. of CGS $16949 / \mathrm{m} l \mathrm{hr}$ after the $21 \mathrm{st}$ administration and declined with half-lives of $10 \mathrm{hr}$ from $4 \mathrm{hr}$ to $24 \mathrm{hr}$ and $65 \mathrm{hr}$ from $48 \mathrm{hr}$ to 168 hr after the administration. The $\mathrm{C}_{\max }$ was 1 .3times higher and the half-life from 4 hr to $24 \mathrm{hr}$ was 1.5 times longer, respectively, than those in the single dosing group ${ }^{2}$.

The pharmacokinetic parameters are also calculated from plasma concentration-time curve of radioactivity in each animal and are summarized by group in Table I.

\section{Excretion of Radioactivity in Urine and Feces}

Table $\mathbb{I}$ shows the comulative excretions of radioactivity in the urine and feces during

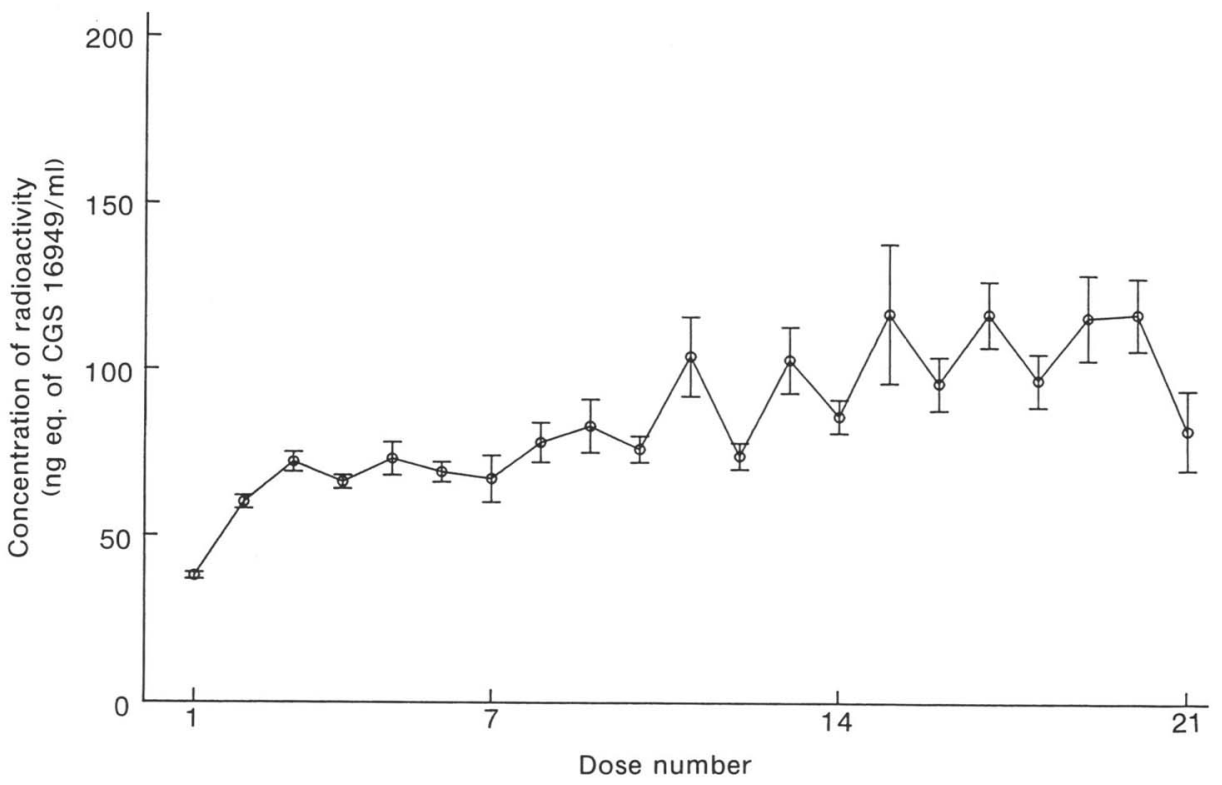

Fig. 2 Plasma concentrations of radioactivity at $24 \mathrm{hr}$ after daily oral administration of ${ }^{14} \mathrm{C}-\mathrm{CGS} 16949 \mathrm{~A} 1 \mathrm{mg} / \mathrm{kg}$ to non-fasted female rats

Data are expressed as the mean values \pm S. E. for three animals. 


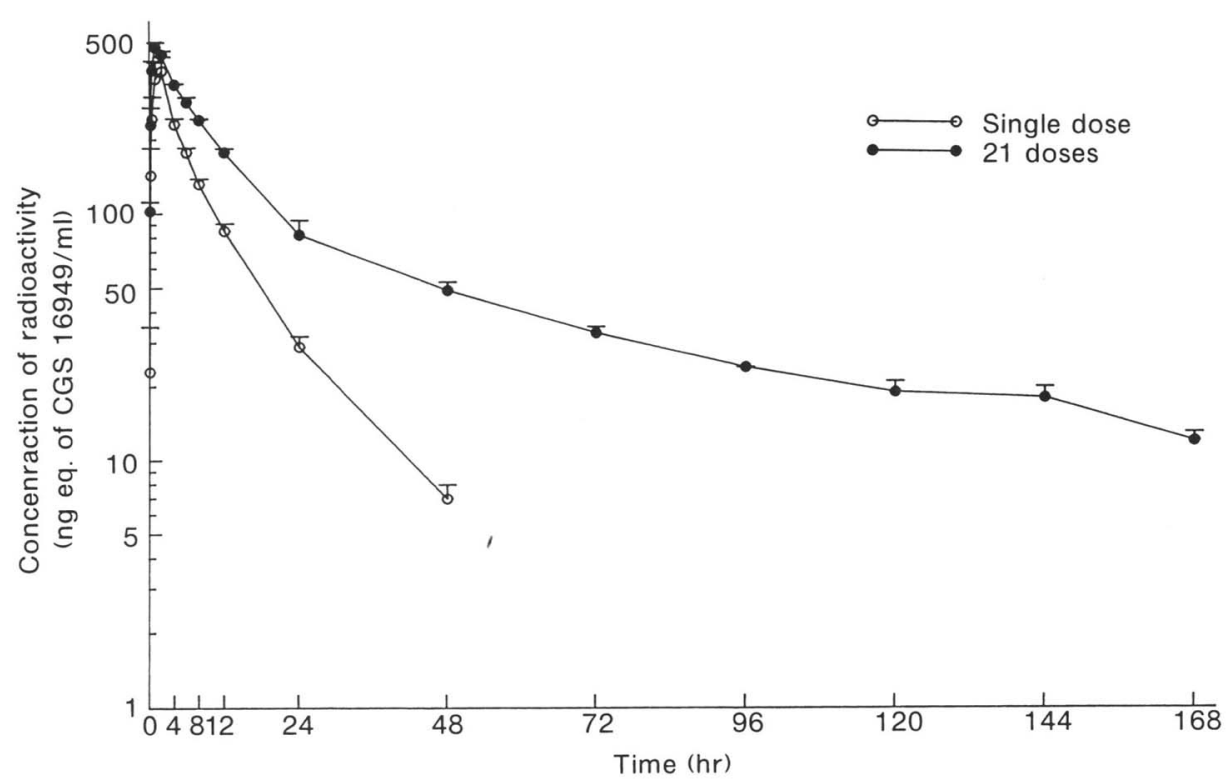

Fig. 3 Plasma concentrations of radioactivity after a single and a 21day period of daily oral administration of ${ }^{14} \mathrm{C}-\mathrm{CGS} 16949 \mathrm{~A} 1 \mathrm{mg} / \mathrm{kg}$ to non-fasted female rats Data are expressed as the mean values \pm S. E. for three animals. Data on single dose are quoted from reference 2 .

Table I Pharmacokinetic parameters of radioactivity in plasma after single and a 21 day period of daily oral administration of ${ }^{14} \mathrm{C}-\mathrm{CGS} 16949 \mathrm{~A} 1 \mathrm{mg} / \mathrm{kg}$ to nonfasted female rats

\begin{tabular}{lcccc}
\hline \hline & \multicolumn{4}{c}{ Pharmacokinetic parameters } \\
\cline { 2 - 5 } & $\begin{array}{c}\mathrm{T}_{\max }{ }^{1)} \\
(\mathrm{hr})\end{array}$ & $\mathrm{C}_{\max ^{2}}$ & $\begin{array}{c}\mathrm{T} 1 / 2 \\
(\mathrm{hr})\end{array}$ & $\mathrm{AUC}^{3)}$ \\
\hline Single dose & & $379 \pm 56$ & $6.8 \pm 0.4(4-24 \mathrm{hr})$ & $3.03 \pm 0.22(0-24 \mathrm{hr})$ \\
& 2 & & & $3.32 \pm 0.27(0-\infty)^{5)}$ \\
21 doses & 1 & $477 \pm 19$ & $10 \pm 1(4-24 \mathrm{hr})$ & $5.09 \pm 0.17(0-24 \mathrm{hr})$ \\
& $(1-2)$ & & $65 \pm 6(48-168 \mathrm{hr})$ & \\
\hline
\end{tabular}

Data are expressed as the mean values \pm S.E. for three animals.

1) : Time to peak concentration $\left(T_{\max }\right)$ values are expressed as the median and range.

2) : ng eq. of CGS $16949 / \mathrm{m} l$.

3) : $\mu$ g eq. of CGS $16949 \cdot \mathrm{hr} / \mathrm{ml}$.

4) : Data on single dose are quoted from reference 2.

5) : AUC $(0-\infty)$ are calculated by the trapezoidal rule from $0 \mathrm{hr}$ to $24 \mathrm{hr}$ and extrapolated from $24 \mathrm{hr}$ to time infinity.

repeated dosing and up to $168 \mathrm{hr}$ after the 21 st dosing. The excretion of radioactivity in the urine and feces reached a steady state after the 4 th dosing.

The urinary, fecal and total excretions of radioactivity were 83.1, 12.8 and 95.9\%, respectively, of the dose within $168 \mathrm{hr}$ after the 21 st dosing. The residual radioactivity in carcass was $0.4 \%$ of the dose $168 \mathrm{hr}$ after the 21 st dosing. 
Table II Cumulative excretions of radioactivity in urine and feces during and after a 21 day period of daily oral administration of ${ }^{14} \mathrm{C}-\mathrm{CGS} 16949$ A $1 \mathrm{mg} / \mathrm{kg}$ to non-fasted female rats

\begin{tabular}{|c|c|c|c|c|}
\hline \multirow{2}{*}{\multicolumn{2}{|c|}{ Number of dosing }} & \multicolumn{3}{|c|}{ Excretion of radioactivity ( $\%$ of cumulative dose } \\
\hline & & Urine & Feces & Total \\
\hline \multicolumn{2}{|l|}{1} & $76.4 \pm 0.9$ & $9.1 \pm 1.0$ & $85.6 \pm 0.1$ \\
\hline \multicolumn{2}{|l|}{2} & $80.3 \pm 1.2$ & $9.0 \pm 0.5$ & $89.3 \pm 0.9$ \\
\hline \multicolumn{2}{|l|}{3} & $82.6 \pm 1.0$ & $9.3 \pm 0.6$ & $91.9 \pm 0.8$ \\
\hline \multicolumn{2}{|l|}{4} & $83.1 \pm 1.0$ & $10.2 \pm 0.5$ & $93.3 \pm 0.9$ \\
\hline \multicolumn{2}{|l|}{5} & $83.5 \pm 1.0$ & $10.2 \pm 0.2$ & $93.7 \pm 0.8$ \\
\hline \multicolumn{2}{|l|}{6} & $83.1 \pm 1.1$ & $10.1 \pm 0.2$ & $93.2 \pm 0.9$ \\
\hline \multicolumn{2}{|l|}{7} & $83.4 \pm 1.0$ & $10.1 \pm 0.3$ & $93.5 \pm 0.7$ \\
\hline \multicolumn{2}{|l|}{8} & $83.4 \pm 1.1$ & $10.3 \pm 0.2$ & $93.7 \pm 1.0$ \\
\hline \multicolumn{2}{|l|}{9} & $83.4 \pm 1.1$ & $10.6 \pm 0.3$ & $94.0 \pm 0.8$ \\
\hline \multicolumn{2}{|l|}{10} & $83.1 \pm 1.1$ & $10.8 \pm 0.4$ & $93.8 \pm 0.8$ \\
\hline \multicolumn{2}{|l|}{11} & $82.8 \pm 1.1$ & $11.2 \pm 0.5$ & $94.0 \pm 0.7$ \\
\hline \multicolumn{2}{|l|}{12} & $82.5 \pm 1.1$ & $11.3 \pm 0.3$ & $93.9 \pm 0.7$ \\
\hline \multicolumn{2}{|l|}{13} & $82.6 \pm 1.1$ & $11.7 \pm 0.5$ & $94.3 \pm 0.6$ \\
\hline \multicolumn{2}{|l|}{14} & $82.5 \pm 1.1$ & $11.8 \pm 0.5$ & $94.3 \pm 0.6$ \\
\hline \multicolumn{2}{|l|}{15} & $82.2 \pm 1.1$ & $12.1 \pm 0.6$ & $94.3 \pm 0.5$ \\
\hline \multicolumn{2}{|l|}{16} & $82.0 \pm 1.1$ & $12.2 \pm 0.6$ & $94.3 \pm 0.5$ \\
\hline \multicolumn{2}{|l|}{17} & $82.1 \pm 1.0$ & $12.2 \pm 0.5$ & $94.3 \pm 0.4$ \\
\hline \multicolumn{2}{|l|}{18} & $82.0 \pm 0.9$ & $12.2 \pm 0.5$ & $94.2 \pm 0.4$ \\
\hline \multicolumn{2}{|l|}{19} & $82.2 \pm 1.0$ & $12.4 \pm 0.6$ & $94.6 \pm 0.4$ \\
\hline \multicolumn{2}{|l|}{21} & $82.0 \pm 1.0$ & $12.6 \pm 0.6$ & $94.6 \pm 0.4$ \\
\hline \multirow[t]{7}{*}{21} & $24 *$ & $82.5 \pm 1.0$ & $12.6 \pm 0.6$ & $95.1 \pm 0.4$ \\
\hline & $48 *$ & $82.9 \pm 0.9$ & $12.7 \pm 0.6$ & $95.6 \pm 0.3$ \\
\hline & $72 *$ & $83.0 \pm 0.9$ & $12.7 \pm 0.6$ & $95.7 \pm 0.2$ \\
\hline & $96 *$ & $83.1 \pm 0.9$ & $12.7 \pm 0.6$ & $95.8 \pm 0.3$ \\
\hline & $120 *$ & $83.1 \pm 0.9$ & $12.7 \pm 0.6$ & $95.8 \pm 0.2$ \\
\hline & $144 *$ & $83.1 \pm 0.9$ & $12.8 \pm 0.6$ & $95.9 \pm 0.3$ \\
\hline & $168 *$ & $83.1 \pm 0.9$ & $12.8 \pm 0.6$ & $95.9 \pm 0.3$ \\
\hline
\end{tabular}

Residual radioactivity in carcass at $168 \mathrm{hr}$ after the 21 st dosing : $0.4 \pm 0.0 \%$ of 21 doses.

Data are expressed as the mean values \pm S. E. for three animals.

*: Hours after the 21st dosing.

Samples were collected for 24 hours after daily dosing and for every 24 hours up to $168 \mathrm{hr}$ after the 21 st dosing.

\section{Whole Body Autoradiograms}

The whole body autoradiograms after the 21st dosing are shown in Fig. 4. High levels of radioactivity were found in the adrenal gland, gastrointestinal contents, urine in urinary bladder, preputial gland, nasal cavity, bile in bile duct (radioactivity was detected in a autoradiogram which is not shown.), ligament, aorta and ovary at 8hr, followed by kidney, liver, mandibular gland, Harderian gland and skin. The radioactivity levels in the blood, brain and eyeball were the lowest.

Although overall radioactivity decreased at $24 \mathrm{hr}$, high levels of radioactivity were still observed in the adrenal gland, nasal cavity, ligament, aorta and gastrointestinal contents, 

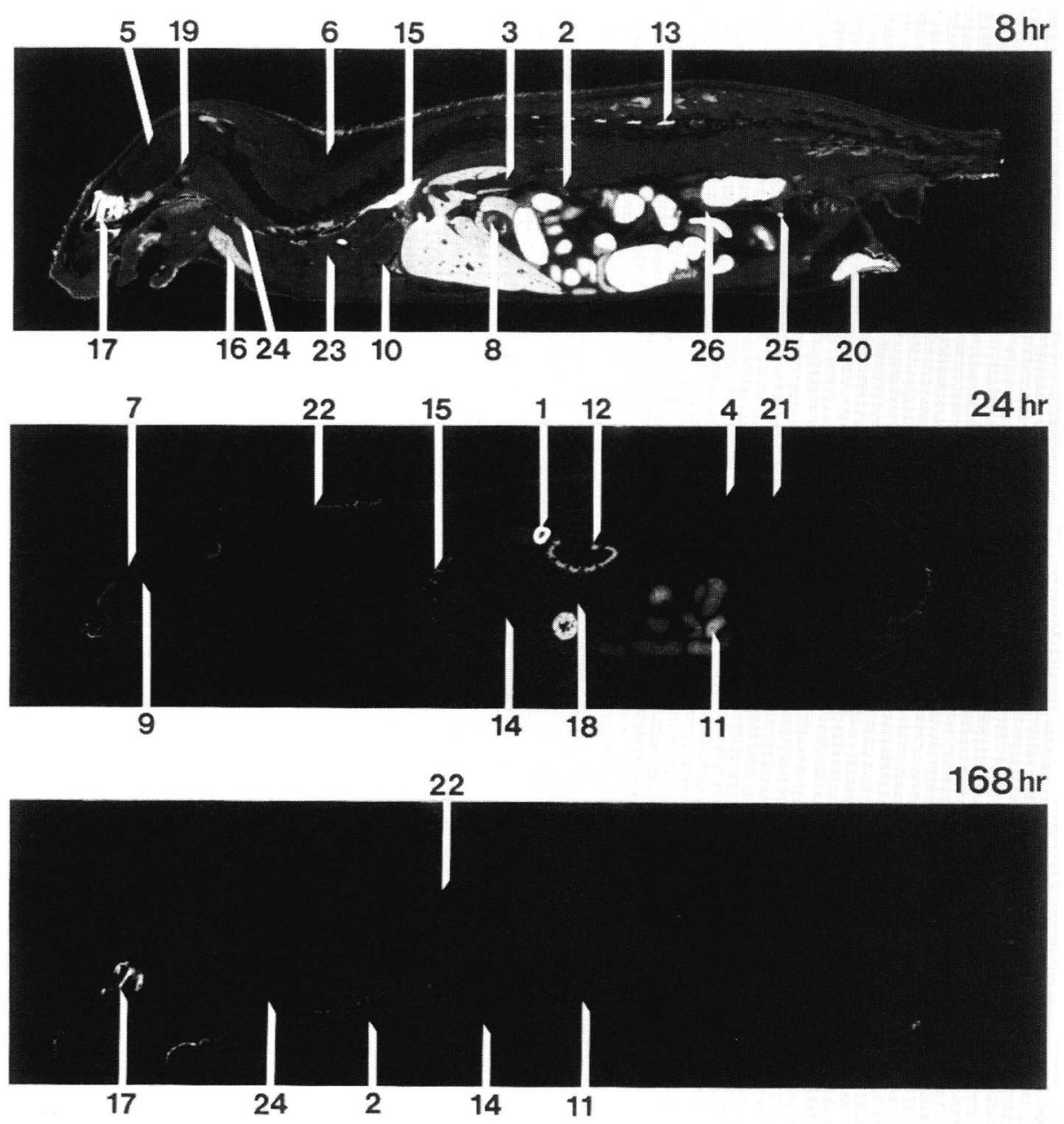

Fig. 4 Autoradiograms showing the distribution of radioactivity after a 21 day period of daily oral administration of ${ }^{14} \mathrm{C}-\mathrm{CGS} 16949 \mathrm{~A} 1 \mathrm{mg} / \mathrm{kg}$ to non-fasted female rats

1. Adrenal gland

2. Aorta

3. Blood

4. Bone marrow

5. Brain

6. Brown fat

7. Eyeball

8. Gastric contents

9. Harderian gland
10. Heart
11. Intestinal contents
12. Kidney
13. Ligament
14. Liver
15. Lung
16. Mandibular gland
17. Nasal cavity
18. Pancreas

19. Pituitary gland

20. Preputial gland

21. Skeletal muscle

22. Skin

23. Thymus

24. Thyroid

25. Urine in bladder

26. Uterus

followed by kidney, skin, mandibular gland and liver.

At $168 \mathrm{hr}$, overall radioactivity further decreased, but high levels of radioactivity were found in the nasal cavity, aorta and kidney, and low levels in the stomach, skin, adrenal gland, intestinal contents, thyroid, lung and liver. 
Table II Tissue concentrations of radioactivity at $24 \mathrm{hr}$ after single and daily oral administration of ${ }^{14} \mathrm{C}$-CGS $16949 \mathrm{~A} 1 \mathrm{mg} / \mathrm{kg}$ to non-fasted female rats

\begin{tabular}{|c|c|c|c|c|}
\hline \multirow[b]{2}{*}{ Tissue } & \multicolumn{4}{|c|}{ Concentration of radioactivity (ng eq. of CGS $16949 / \mathrm{g}$ or $\mathrm{m} l$ ) } \\
\hline & single dose & 7 doses & 14 doses & 21 doses \\
\hline Plasma & $35 \pm 2$ & $63 \pm 1$ & $65 \pm 3$ & $69 \pm 6$ \\
\hline Blood & $31 \pm 1$ & $61 \pm 1$ & $68 \pm 4$ & $81 \pm 7$ \\
\hline Cerebrum & $23 \pm 1$ & $40 \pm 2$ & $46 \pm 2$ & $58 \pm 7$ \\
\hline Cerebellum & $20 \pm 1$ & $36 \pm 1$ & $40 \pm 3$ & $50 \pm 6$ \\
\hline Spinal cord & $21 \pm 1$ & $36 \pm 1$ & $38 \pm 3$ & $49 \pm 6$ \\
\hline Pituitary gland & $46 \pm 9$ & $61 \pm 6$ & $72 \pm 8$ & $82 \pm 12$ \\
\hline Eyeball & $26 \pm 1$ & $52 \pm \quad 2$ & $55 \pm 3$ & $75 \pm \quad 8$ \\
\hline Harderian gland & $55 \pm 2$ & $93 \pm 2$ & $91 \pm 9$ & $110 \pm 11$ \\
\hline Thyroid & $54 \pm 4$ & $147 \pm 14$ & $147 \pm 5$ & $218 \pm 38$ \\
\hline Mandibular ${ }^{\mathrm{a})}$ & $48 \pm 2$ & $80 \pm 1$ & $81 \pm 9$ & $98 \pm 12$ \\
\hline Lymph node & $32 \pm 1$ & $55 \pm 3$ & $58 \pm 2$ & $70 \pm 6$ \\
\hline Thymus & $28 \pm 1$ & $61 \pm 9$ & $43 \pm 3$ & $54 \pm \quad 4$ \\
\hline Heart & $38 \pm 3$ & $71 \pm 3$ & $78 \pm 5$ & $90 \pm 6$ \\
\hline Lung & $75 \pm 6$ & $162 \pm 6$ & $187 \pm 3$ & $225 \pm 6$ \\
\hline Liver & $145 \pm 7$ & $224 \pm 9$ & $211 \pm 9$ & $260 \pm 26$ \\
\hline Kidney & $104 \pm 1$ & $188 \pm 3$ & $234 \pm 16$ & $275 \pm 19$ \\
\hline Adrenal gland & $1226 \pm 30$ & $1470 \pm 282$ & $2076 \pm 340$ & $1622 \pm 342$ \\
\hline Spleen & $39 \pm 3$ & $70 \pm 1$ & $76 \pm \quad 4$ & $117 \pm 11$ \\
\hline Pancreas & $61 \pm 2$ & $90 \pm 1$ & $93 \pm 11$ & $107 \pm 11$ \\
\hline Fat & $13 \pm 0$ & $20 \pm 2$ & $20 \pm 3$ & $20 \pm \quad 2$ \\
\hline Brown fat & $46 \pm 4$ & $76 \pm 6$ & $79 \pm 6$ & $87 \pm 2$ \\
\hline Skeletal muscle & $28 \pm 0$ & $47 \pm 3$ & $47 \pm \quad 4$ & $64 \pm \quad 7$ \\
\hline Skin & $50 \pm 13$ & $164 \pm 9$ & $170 \pm 7$ & $201 \pm 25$ \\
\hline Bone marrow & $37 \pm 3$ & $54 \pm 1$ & $55 \pm 6$ & $70 \pm \quad 4$ \\
\hline Aorta & $72 \pm 9$ & $196 \pm 13$ & $452 \pm 34$ & $639 \pm 87$ \\
\hline Sciatic nerve & $31 \pm 2$ & $57 \pm 3$ & $69 \pm 5$ & $96 \pm 7$ \\
\hline Ovary & $64 \pm 14$ & $117 \pm 11$ & $108 \pm 16$ & $121 \pm 12$ \\
\hline Uterus & $34 \pm 1$ & $66 \pm 10$ & $61 \pm 2$ & $84 \pm 13$ \\
\hline Urinary bladder & $40 \pm 7$ & $56 \pm 7$ & $69 \pm 11$ & $100 \pm 17$ \\
\hline Stomach & $239 \pm 13$ & $292 \pm 4$ & $259 \pm 13$ & $344 \pm 22$ \\
\hline Duodenum & $42 \pm 6$ & $52 \pm 6$ & $46 \pm 10$ & $79 \pm 9$ \\
\hline Ileum & $97 \pm 15$ & $90 \pm 9$ & $68 \pm 9$ & $127 \pm \quad 4$ \\
\hline Cecum & $141 \pm 20$ & $150 \pm 39$ & $133 \pm 45$ & $234 \pm 49$ \\
\hline Colon & $104 \pm 2$ & $110 \pm 21$ & $99 \pm 30$ & $98 \pm 20$ \\
\hline
\end{tabular}

Data are expressed as the mean values \pm S.E. for three animals.

a) : Mandibular gland.

Data on single dose are quoted from reference 2 .

\section{Radioactivity Concentration in Tissue}

The radioactivity concentrations in the tissues $24 \mathrm{hr}$ after the 7 th, 14th and 21st dosing are shown in Table $\mathbb{I I}$, compared with the level after a single administraiton ${ }^{2)}$. The radioactivity concentration after the 7 th dosing increased, in comparison with the concentration after a single administration and the radioactivity levels after the 14th dosing were similar to those after the 7 th dosing. 
Table $\mathrm{N}$ Tissue concentrations of radioactivity after a 21day period of daily oral administration of ${ }^{14} \mathrm{C}-\mathrm{CGS} 16949 \mathrm{~A} \mathrm{mg} / \mathrm{kg}$ to non-fasted female rats

\begin{tabular}{|c|c|c|c|c|c|c|c|}
\hline \multirow[b]{2}{*}{ Tissue } & \multicolumn{7}{|c|}{ Concentration of radioactivity (ng eq. of CGS $16949 / \mathrm{g} \mathrm{m} l$ ) } \\
\hline & $2 \mathrm{hr}$ & $8 \mathrm{hr}$ & $24 \mathrm{hr}$ & $72 \mathrm{hr}$ & $168 \mathrm{hr}$ & $336 \mathrm{hr}$ & $672 \mathrm{hr}$ \\
\hline Plasma & $410 \pm 24$ & $235 \pm 18$ & $69 \pm 6$ & $18 \pm 1$ & $7 \pm 0$ & N.D. & N.D. \\
\hline Blood & $448 \pm 25$ & $245 \pm 19$ & $81 \pm 7$ & $37 \pm 4$ & $26 \pm 1$ & $15 \pm 1$ & $6 \pm 0$ \\
\hline Cerebrum & $714 \pm \quad 28$ & $237 \pm 31$ & $58 \pm 7$ & $24 \pm 1$ & $16 \pm 2$ & $8 \pm 1$ & $5 \pm 0$ \\
\hline Cerebellum & $578 \pm \quad 23$ & $202 \pm \quad 26$ & $50 \pm 6$ & $22 \pm 1$ & $13 \pm 2$ & $7 \pm 1$ & $4 \pm 0$ \\
\hline Spinal cord & $616 \pm 26$ & $208 \pm 24$ & $49 \pm 6$ & $23 \pm 1$ & $15 \pm 2$ & $8 \pm 1$ & $6 \pm 0$ \\
\hline Pituitary gland & $1055 \pm 122$ & $365 \pm \quad 28$ & $82 \pm 12$ & N.D. & N.D. & N.D. & N.D. \\
\hline Eyeball & $354 \pm$ & $202 \pm \quad 11$ & $75 \pm 8$ & $33 \pm 2$ & $22 \pm 2$ & $12 \pm 1$ & $10 \pm 0$ \\
\hline Harderian gland & $2101 \pm 73$ & $614 \pm \quad 41$ & $110 \pm 11$ & $36 \pm 2$ & $20 \pm 6$ & $12 \pm 2$ & $10 \pm 1$ \\
\hline Thyroid & $873 \pm 70$ & $440 \pm \quad 20$ & $218 \pm 38$ & $91 \pm 16$ & $88 \pm 11$ & $57 \pm 7$ & $33 \pm 6$ \\
\hline Mandibular ${ }^{\mathrm{a})}$ & $2092 \pm 304$ & $671 \pm \quad 49$ & $98 \pm 12$ & $28 \pm 2$ & $18 \pm 3$ & $8 \pm 1$ & $8 \pm 1$ \\
\hline Lymph node & $666 \pm \quad 25$ & $290 \pm 27$ & $70 \pm 6$ & $28 \pm 3$ & $18 \pm 3$ & $11 \pm 1$ & $10 \pm 0$ \\
\hline Thymus & $610 \pm 26$ & $257 \pm \quad 23$ & $54 \pm \quad 4$ & $15 \pm 1$ & $9 \pm 1$ & $5 \pm 1$ & $4 \pm 1$ \\
\hline Heart & $719 \pm \quad 15$ & $324 \pm \quad 32$ & $90 \pm 6$ & $37 \pm 2$ & $22 \pm 3$ & $11 \pm 0$ & $7 \pm 1$ \\
\hline Lung & $1313 \pm 65$ & $593 \pm 54$ & $225 \pm 6$ & $154 \pm 10$ & $118 \pm 5$ & $94 \pm 11$ & $88 \pm 1$ \\
\hline Liver & $2489 \pm 69$ & $1163 \pm 94$ & $260 \pm 26$ & $82 \pm 5$ & $44 \pm 7$ & $19 \pm 3$ & $11 \pm 1$ \\
\hline Kidney & $1765 \pm 59$ & $878 \pm 61$ & $275 \pm 19$ & $170 \pm 22$ & $122 \pm 2$ & $53 \pm 4$ & $49 \pm 2$ \\
\hline Adrenal gland & $12547 \pm 2526$ & $8406 \pm 1956$ & $1622 \pm 342$ & $347 \pm 67$ & $131 \pm 54$ & $64 \pm 17$ & $22 \pm 1$ \\
\hline Spleen & $880 \pm 30$ & $401 \pm \quad 25$ & $117 \pm 11$ & $69 \pm 5$ & $51 \pm 2$ & $48 \pm 5$ & $33 \pm 4$ \\
\hline Pancreas & $1061 \pm 48$ & $463 \pm \quad 40$ & $107 \pm 11$ & $29 \pm 2$ & $18 \pm 4$ & $8 \pm 0$ & $5 \pm 0$ \\
\hline Fat & $287 \pm \quad 62$ & $103 \pm 11$ & $20 \pm \quad 2$ & $5 \pm 0$ & $4 \pm 2$ & N.D. & N.D. \\
\hline Brown fat & $670 \pm$ & $283 \pm \quad 19$ & $87 \pm 2$ & $26 \pm 2$ & $17 \pm 1$ & $8 \pm 2$ & $5 \pm 1$ \\
\hline Skeletal muscle & $494 \pm$ & $239 \pm 14$ & $64 \pm 7$ & $20 \pm 3$ & $12 \pm 3$ & $6 \pm 0$ & $5 \pm 0$ \\
\hline Skin & $617 \pm \quad 13$ & $356 \pm 9$ & $201 \pm 25$ & $142 \pm 16$ & $129 \pm 12$ & $92 \pm 8$ & $88 \pm 6$ \\
\hline Bone marrow & $879 \pm 100$ & $355 \pm \quad 41$ & $70 \pm \quad 4$ & $22 \pm 3$ & $15 \pm 2$ & N.D. & N.D. \\
\hline Aorta & $1364 \pm 117$ & $1107 \pm 90$ & $639 \pm 87$ & $559 \pm 23$ & $524 \pm 38$ & $482 \pm 13$ & $446 \pm 12$ \\
\hline Sciatic nerve & $673 \pm \quad 17$ & $322 \pm \quad 20$ & $96 \pm 7$ & $39 \pm 2$ & $34 \pm 2$ & $22 \pm 2$ & $21 \pm 1$ \\
\hline Ovary & $1066 \pm 139$ & $577 \pm 113$ & $121 \pm 12$ & $44 \pm 0$ & $32 \pm 5$ & $24 \pm 2$ & $16 \pm 1$ \\
\hline Uterus & $538 \pm 10$ & $265 \pm \quad 35$ & $84 \pm 13$ & $29 \pm 2$ & $19 \pm 2$ & $11 \pm 2$ & $11 \pm 1$ \\
\hline Urinary bladder & $974 \pm 404$ & $374 \pm \quad 64$ & $100 \pm 17$ & $50 \pm 4$ & $38 \pm 5$ & $31 \pm 2$ & $31 \pm 4$ \\
\hline Stomach & $2389 \pm 73$ & $733 \pm 124$ & $344 \pm 22$ & $213 \pm 9$ & $112 \pm 28$ & $65 \pm 12$ & $37 \pm 5$ \\
\hline Duodenum & $637 \pm \quad 45$ & $276 \pm 50$ & $79 \pm 9$ & $26 \pm 3$ & $21 \pm 1$ & $15 \pm 2$ & $13 \pm 1$ \\
\hline Ilem & $653 \pm 143$ & $395 \pm 68$ & $127 \pm \quad 4$ & $31 \pm 2$ & $22 \pm 3$ & $15 \pm 2$ & $11 \pm 1$ \\
\hline Cecum & $596 \pm 39$ & $1052 \pm 31$ & $234 \pm 49$ & $39 \pm 4$ & $34 \pm 3$ & $22 \pm 4$ & $16 \pm 2$ \\
\hline Colon & $594 \pm \quad 49$ & $353 \pm 56$ & $98 \pm 20$ & $32 \pm 2$ & $26 \pm 2$ & $17 \pm 2$ & $16 \pm 1$ \\
\hline
\end{tabular}

Data are expressed as the mean values $\pm \mathrm{S}$. E. of three animals.

a) : Mandibular gland.

N.D. : Not detected.

The radioactivity concentration in the skin $24 \mathrm{hr}$ after the 7 th dosing was 3 . 3times higher than that after single dosing. The eyeball, thyroid, thymus, lung and aorta showed 2.0 2.7times higher concentrations than those after single dosing. Other tissues showed less than 2times of the concentrations after single dose.

The radioactivity concentrations in the aorta, thyroid and skin after the 21 st dosing increased to $8.9,4.0$ and 4.0 times higher concentrations, respectively, of those after 
single dosing.

The radioactivity concentrations in the tissues after the 21st dosing are shown in Table N.

At $2 \mathrm{hr}$ after the 21 st dosing, the radioactivity concentration in the adrenal gland was the highest, which was 31times higher than the concentration in the plasma (410ng eq. of CGS $16949 / \mathrm{ml}$ ). The liver, stomach, Harderian gland and mandibular gland showed $5 \sim 6$ times higher radioactivity concentrations than that in the plasma. The radioactivity concentrations in the thymus, colon, cerebellum, cecum, uterus, skeletal muscle, blood, eyeball and fat were similar to that in the plasma.

At $8 \mathrm{hr}$, the radioactivity concentration in the adrenal gland was the highest, which was 36times higher than that in the plasma (235ng eq. of CGS $16949 / \mathrm{m} l$ ). The radioactivity in the liver and aorta showed 5times higher concentrations than that in plasma.

At $24 \mathrm{hr}$, the concentration in the aorta decreased to $47 \%$ of the maximum. The radioactivity concentrations in the thymus, cerebellum, cerebrum, bone marrow, spinal cord, pituitary gland, fat, Harderian gland and mandibular gland showed 5-9\% of each maximum concentration, and those in the other tissues were $10-33 \%$ of the maximum.

At $72 \mathrm{hr}$, the aorta and skin showed 41 and $23 \%$, respectively, of each maximum concentration. The radioactivity concentration in the pituitary gland was below the limit of detection at $72 \mathrm{hr}$. At $168 \mathrm{hr}$, the radioactivity concentration in the aorta and skin was 38 and $21 \%$ of the maximum, respectively, and that of thyroid, lung, kidney, eyeball, blood and spleen was $6-10 \%$. The radioactivity of the other tissues decreased to less than $5 \%$ of those maximum concentrations.

At $672 \mathrm{hr}$, the aorta and skin showed 33 and $14 \%$, respectively, of each maximum concentration of radioactivity, and the lung, sciatic nerve and spleen showed $4-7 \%$ of the maximum. The radioactivity concentrations in the plasma, pituitary gland, fat and bone marrow were below the limit of detection. The radioactivity of the other tissues decreased to less than $3 \%$ of those maximum concentrations.

\section{Metabolites}

The HPLC chromatograms of metabolites in the plasma, urine and liver after the 21 st dosing of ${ }^{14} \mathrm{C}-\mathrm{CGS} 16949 \mathrm{~A} 1 \mathrm{mg} / \mathrm{kg}$ to female rats are shown in Fig. $5 \sim 7$ and the relative amounts of metabolites in the plasma, urine, faces, liver and kidney are shown in Table $\mathrm{V} \sim \mathrm{X}$. The unknown metabolites were named in order of retention time, as those in the single dosing group ${ }^{2}$. The retention times of each fraction for metabolites in plasma, urine, feces, liver and kidney were summarized in Table V.

\section{1) Metabolites in plasma}

After repeated administration of ${ }^{14} \mathrm{C}-\mathrm{CGS} 16949 \mathrm{~A} 1 \mathrm{mg} / \mathrm{kg}$ to female rats, the concentration of unchanged CGS 16949 was $198 \mathrm{ng}$ eq. of CGS $16949 / \mathrm{m} l$ at $2 \mathrm{hr}$ and accounted for $48.1 \%$ of total radioactivity (Table V). CGP 45383 (trans-8-hydroxy metabolite), CGP 45384 (cis-8-hydroxy metabolite) and CGP 45385 (8-oxo metabolite) was observed 9.1\%, $8.0 \%$ and $9.3 \%$, respectively, of total radioactivity in plasma. The relative amount of the metabolite with hydantoin-type structure, MP2 was $9.6 \%$ of radioactivity in plasma at $2 \mathrm{hr}$. 
Table V Retention times of each fraction for metabolites in HPLC chromatograms for plasma, urine, feces, liver and kidney

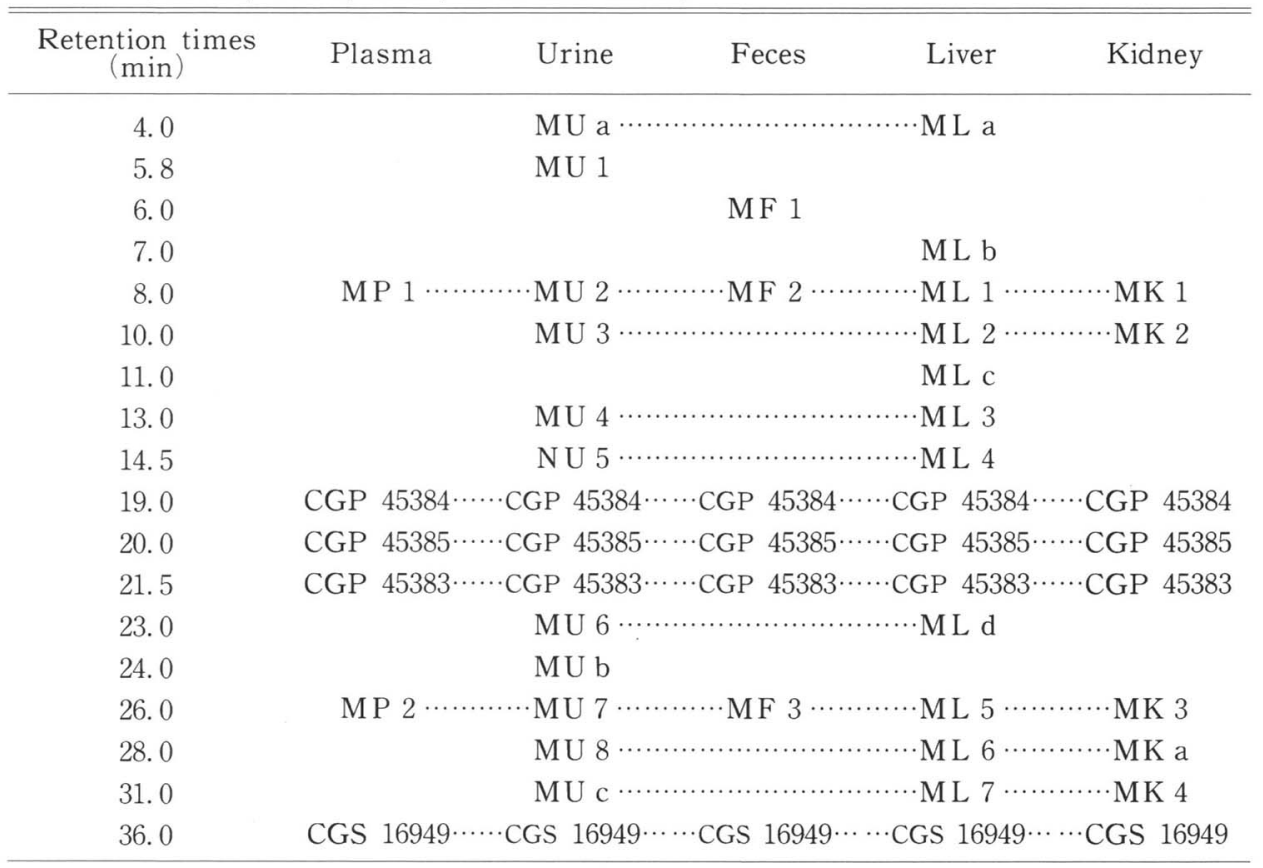

Each sample was obtained after a 21 day period of daily oral administration of ${ }^{14} \mathrm{C}-$ CGS $16949 \mathrm{~A} \mathrm{lmg} / \mathrm{kg}$ to non-fasted female rats.

The analytical methods are described in the section "MATERIALS AND METHODS", 14. Analysis of metabolites in reference 2 .

At $8 \mathrm{hr}$, the relative amount of CGS 16949 decreased to $17.2 \%$ of radioactivity and its concentration was $42 \mathrm{ng}$ eq. of CGS $16949 / \mathrm{ml}$. CGP 45383 decreased to $7.9 \%$ and CGP 45384 and CGP 45385 and MP2 increased to $13.6,15.7$ and $22.1 \%$, respectively, of total radioactivity in plasma.

At $24 \mathrm{hr}$, the radioactivity concentraitons in the fractions corresponded to CGS 16949, CGP 45383 and CGP 45384 were below the limit of detection. The relative amount of CGP 45385 was $8.6 \%$ and that of MP2 increased to $35.4 \%$ of radioactivity at $24 \mathrm{hr}$.

Compared with the data after single dosing ${ }^{2}$, the relative amount of unchanged CGS 16949 decreased and that of MP2 increased. There were no significant differences between the concentration of CGS 16949 after single (2hr: 208 \pm 23 (mean \pm S.E.), 8hr : 35 \pm 4 ng eq. of CGS $16949 / \mathrm{ml}$ ) and the 21st dosing (2hr : 198 \pm 19 , $8 \mathrm{hr}: 42 \pm 10 \mathrm{ng}$ eq. of CGS 16949/ $\mathrm{m} l)$.

\section{2) Metabolites in urine}

The relative amounts of CGS 16949, CGP 45383, CGP 45384 and CGP 45385 were 13.2 $\%, 32.9 \%, 24.3 \%$ and $3.5 \%$ of urinary radioactivity, respectively (Table VII). Eleven kinds of unknown metabolites were found and each ratio was less than $7.9 \%$ of urinary radioactivity. The relative amounts of unchanged compound and main metabolites were similar to that found in the single dosing group ${ }^{2}$.

\section{3) Metabolites in feces}




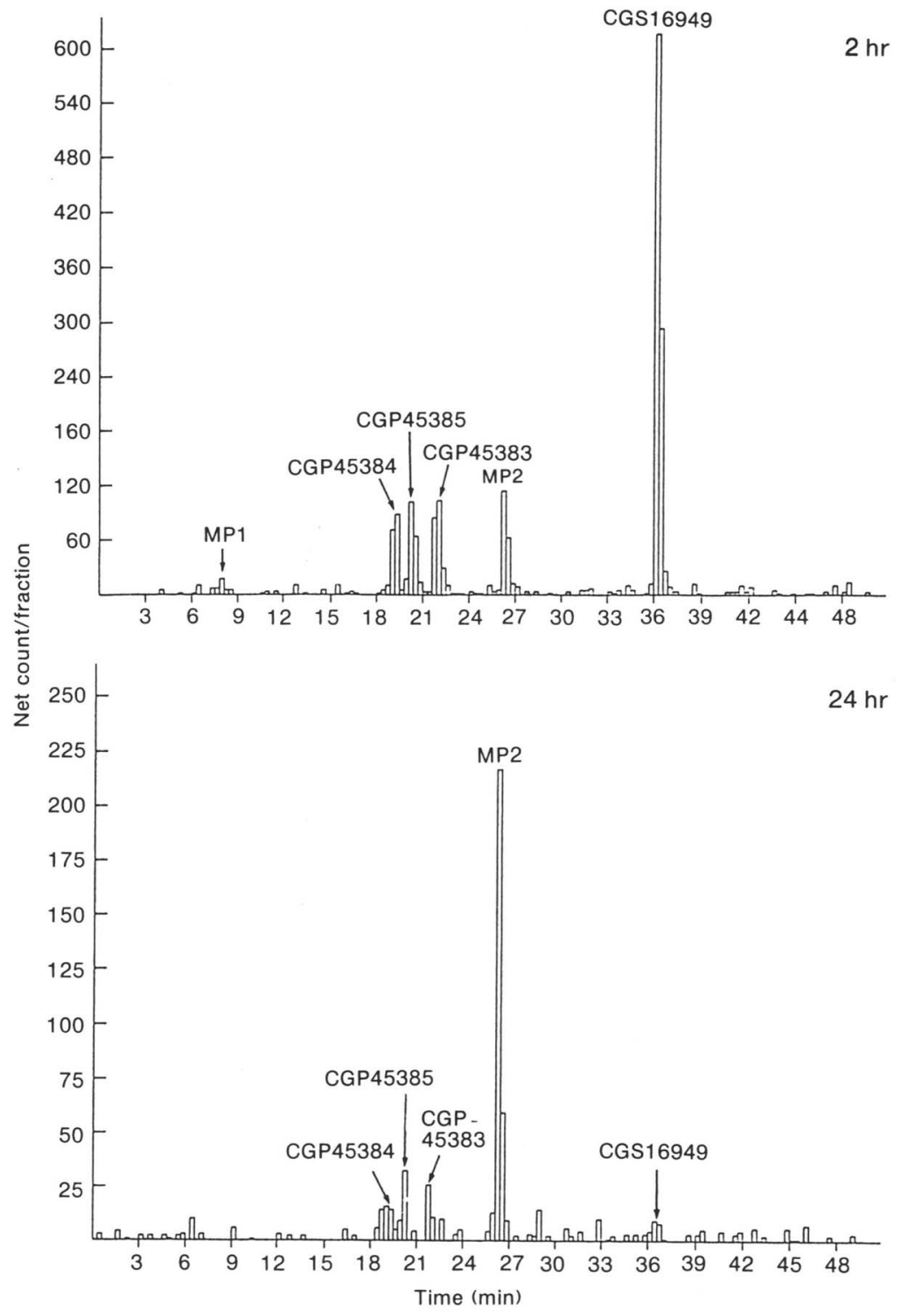

Fig. 5 HPLC chromatogram of radioactivity in plasma (2hr, 24hr) after a 21day period of daily oral administration of ${ }^{14} \mathrm{C}-\mathrm{CGS}$ $16949 \mathrm{~A} 1 \mathrm{mg} / \mathrm{kg}$ to non-fasted female rats

The relative amounts of CGS 16949, CGP 45383 and CGP 45384 were 6.6\%, 28.0\% and $6.7 \%$ of fecal radioactivity, respectively (Table VII). CGP 45385 was not detected. Two kinds of unknown metabolites, MF2 and MF3 accounted for $7.2 \%$ and $4.1 \%$ of radioactivity in feces, respectively.

Compared with the data after single dosing ${ }^{2)}$, the relative amount of CGS 16949 decreased and that of CGP 45383 increased.

\section{4) Metabolites in liver}


Table VI Composition of CGS 16949 and its metabolites in plasma after a 21 day period of daily oral administration of ${ }^{14} \mathrm{C}-\mathrm{CGS} 16949 \mathrm{~A}$ $1 \mathrm{mg} / \mathrm{kg}$ to non-fasted female rats

\begin{tabular}{lccc}
\hline \hline \multirow{2}{*}{$\begin{array}{l}\text { CGS } 16949 \text { and } \\
\text { its metabolites }\end{array}$} & \multicolumn{3}{c}{$\%$ of radioactivity in plasma } \\
\cline { 2 - 4 } CGS 16949 & $48.1 \pm 2.4$ & $17.2 \pm 3.0$ & $24 \mathrm{hr}$ \\
CGP 45383 & $9.1 \pm 0.9$ & $7.9 \pm 0.3$ & N.D. \\
CGP 45384 & $8.0 \pm 1.6$ & $13.6 \pm 1.2$ & N.D. \\
CGP 45385 & $9.3 \pm 0.8$ & $15.7 \pm 1.2$ & $8.6 \pm 2.1$ \\
MP1 & N.D. & N.D. & N.D. \\
MP2 & $9.6 \pm 0.2$ & $22.1 \pm 1.3$ & $35.4 \pm 0.4$ \\
\hline Others & $9.7 \pm 1.6$ & $14.0 \pm 1.4$ & $30.9 \pm 2.3$ \\
\hline Recovery & $93.8 \pm 0.3$ & $90.5 \pm 0.1$ & $74.9 \pm 1.8$ \\
\hline
\end{tabular}

Data are expressed as the mean values \pm S.E. for three animals. N.D. : Not detected.

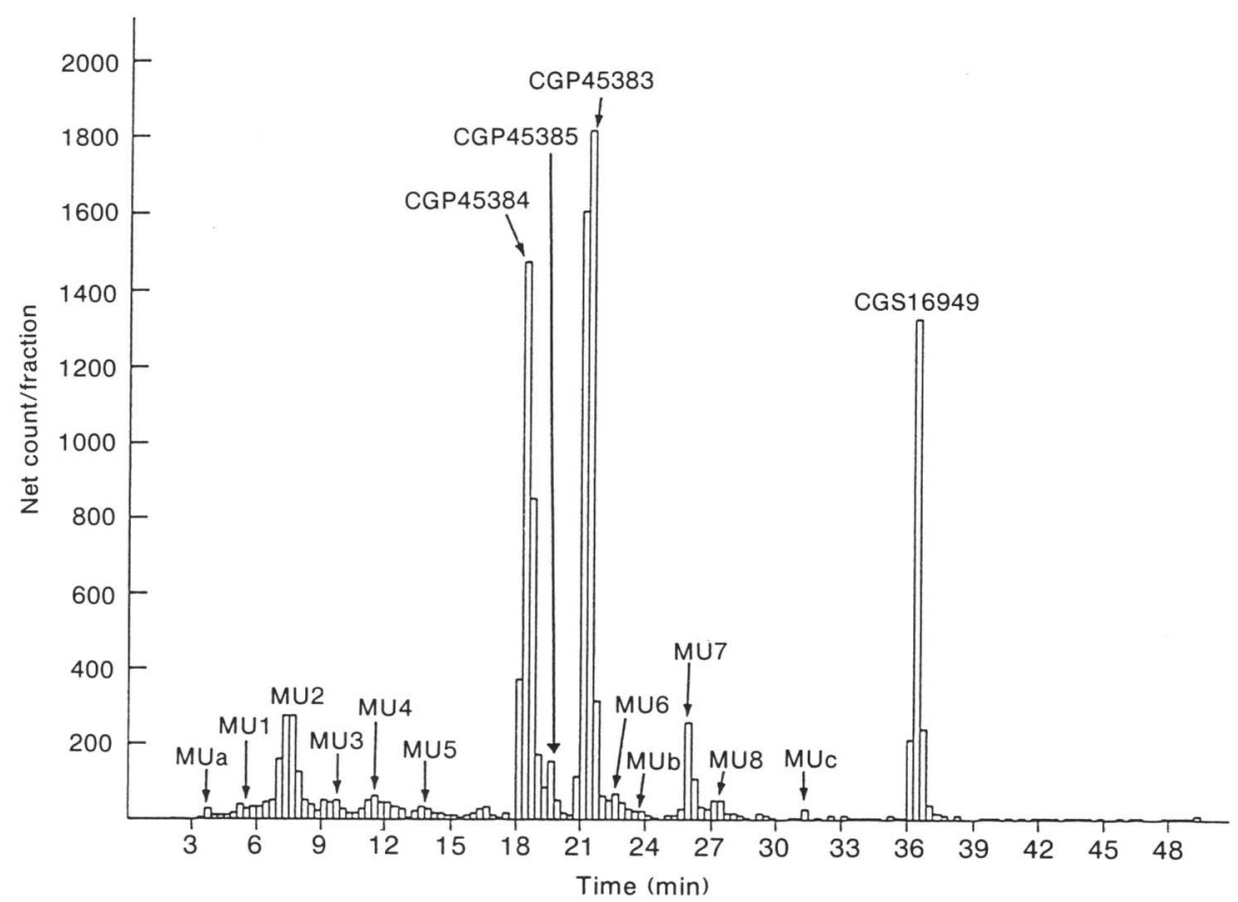

Fig. 6 HPLC chromatogram of radioactivity in urine (0-24hr) after a 21day period of daily oral administration of ${ }^{14} \mathrm{C}$-CGS $16949 \mathrm{~A} 1 \mathrm{mg} / \mathrm{kg}$ to non-fasted female rats

The radioactivity concentration of CGS 16949 in the liver at $2 \mathrm{hr}$ after 21st dosing was $1048 \mathrm{ng}$ eq. of CGS $16949 / \mathrm{g}$, which corresponded to $42.2 \%$ of radioactivity in the liver (Table X). The relative amounts of CGP 45383, CGP 45384 and CGP 45385 were 4.8\%, $6.7 \%$ and $2.3 \%$ of radioactivity, respectively. 
Table VII Composion of CGS 16949 and its metabolites in urine $(0-24 \mathrm{hr})$ after a 21 day period of daily oral administration of ${ }^{14} \mathrm{C}$-CGS $16949 \mathrm{~A} 1 \mathrm{mg} / \mathrm{kg}$ to non-fasted female rats

\begin{tabular}{lr}
\hline \hline $\begin{array}{c}\text { CGS 16949 and } \\
\text { its metabolites }\end{array}$ & $\begin{array}{c}\text { \% of radioactivity } \\
\text { in urine }\end{array}$ \\
\hline CGS 16949 & $13.2 \pm 1.3$ \\
CGP 45383 & $32.9 \pm 0.5$ \\
CGP 45384 & $24.3 \pm 0.6$ \\
CGP 45385 & $3.5 \pm 0.5$ \\
MU1 & $1.8 \pm 0.3$ \\
MU2 & $7.9 \pm 0.8$ \\
MU3 & $1.2 \pm 0.3$ \\
MU4 & $2.3 \pm 0.3$ \\
MU5 & $1.0 \pm 0.1$ \\
MU6 & $1.3 \pm 0.0$ \\
MU7 & $3.7 \pm 0.1$ \\
MU8 & $1.0 \pm 0.1$ \\
MUa & $0.4 \pm 0.1$ \\
MUb & $0.4 \pm 0.1$ \\
MUc & $0.4 \pm 0.1$ \\
\hline Others & $4.2 \pm 0.2$ \\
\hline Recovery & $99.5 \pm 0.1$ \\
\hline
\end{tabular}

Data are expressed as the mean values \pm S. E. for three animals.

Table VII Composition of CGS 16949 and its metabolites in feces $(0-24 \mathrm{hr})$ after a 21day period of daily oral administration of ${ }^{14} \mathrm{C}-\mathrm{CGS} 16949 \mathrm{~A} 1 \mathrm{mg} / \mathrm{kg}$ to non-fasted female rats

\begin{tabular}{lc}
\hline $\begin{array}{c}\text { CGS } 16949 \text { and } \\
\text { its metabolites }\end{array}$ & $\begin{array}{c}\% \text { of radioactivity } \\
\text { in feces }\end{array}$ \\
\hline CGS 16949 & $6.6 \pm 0.7$ \\
CGP 45383 & $28.0 \pm 3.7$ \\
CGP 45384 & $6.7 \pm 1.5$ \\
CGP 45385 & N.D. \\
MF1 & N.D. \\
MF2 & $7.2 \pm 1.3$ \\
MF3 & $4.1 \pm 0.9$ \\
\hline Others & $32.7 \pm 2.6$ \\
\hline Recovery & $85.4 \pm 1.6$ \\
\hline Data are expressed as the mean values \pm S.E. \\
for three animals. \\
N.D. : Not detected.
\end{tabular}




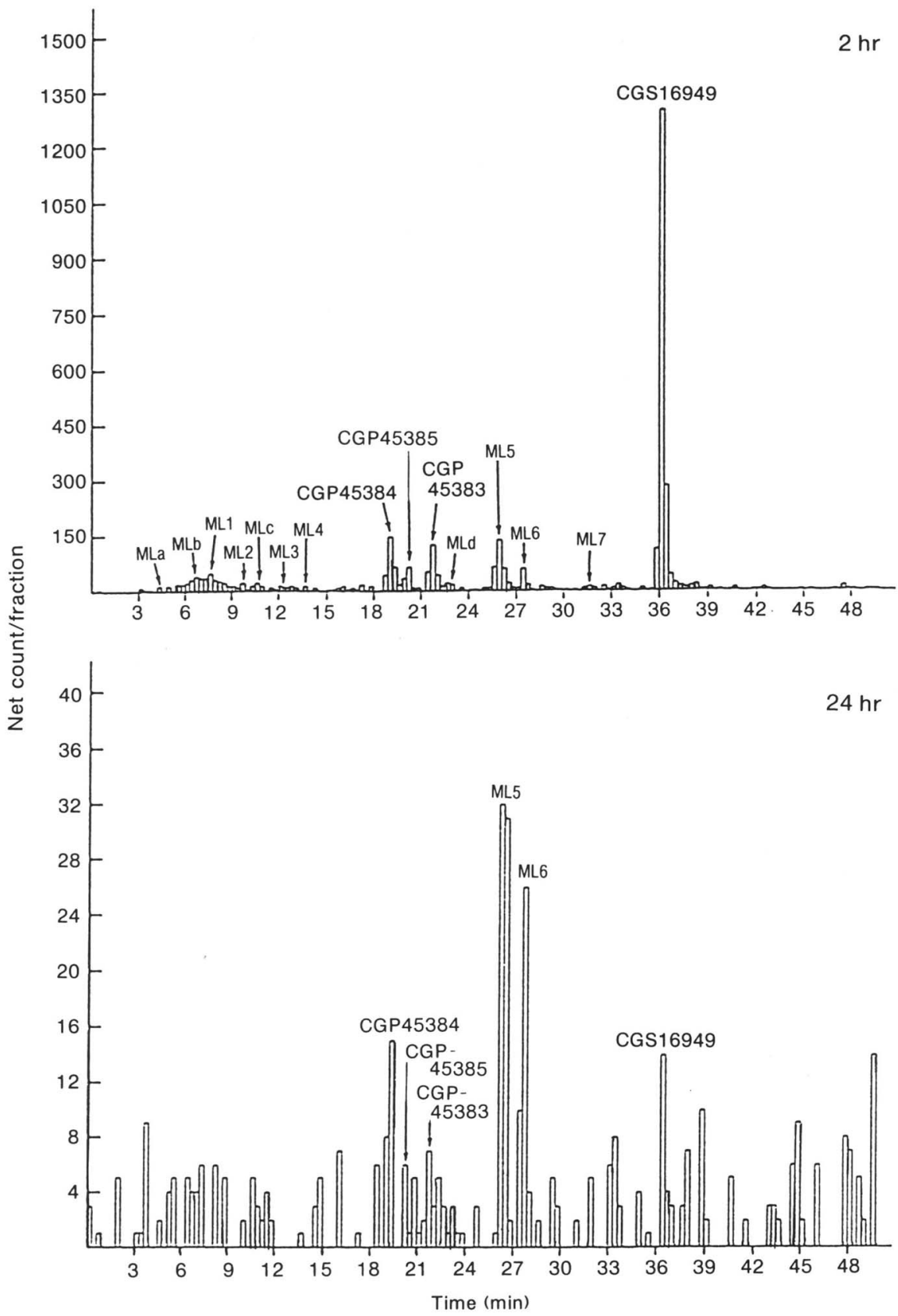

Fig. 7 HPLC chromatograms of radioactivity in liver (2hr, 24hr) after a 21day period of daily oral administration of ${ }^{14} \mathrm{C}-\mathrm{CGS} 16949 \mathrm{~A} 1 \mathrm{mg} / \mathrm{kg}$ to nonfasted female rats

At $8 \mathrm{hr}$, the relative amount of CGS 16949 decreased to $23.1 \%$ of radioactivity and its concentration was 275ng eq. of CGS $16949 / \mathrm{g}$. CGP 45383, CGP 45384 and CGP 45385 accounted for $6.2 \%, 14.3 \%$ and $2.9 \%$ of radioactivity, respectively, and the relative amounts of ML1, ML5 and ML6 were 2.5 9.4\% of radioactivity. 
Table X Composition of CGS 16949 and its metabolites in liver after a 21day period of daily oral administration of ${ }^{14} \mathrm{C}-\mathrm{CGS} 16949 \mathrm{~A}$ $1 \mathrm{mg} / \mathrm{kg}$ to non-fasted female rats

\begin{tabular}{lrrr}
\hline \hline \multirow{2}{*}{ CGS 16949 and } & \multicolumn{3}{c}{$\%$ of radioactivity in liver } \\
\cline { 2 - 4 } its metabolites & \multicolumn{1}{c}{$2 \mathrm{hr}$} & \multicolumn{1}{c}{$8 \mathrm{hr}$} & $24 \mathrm{hr}$ \\
\hline CGS 16949 & $42.2 \pm 1.9$ & $23.1 \pm 3.6$ & N.D. \\
CGP 45383 & $4.8 \pm 0.5$ & $6.2 \pm 0.5$ & N.D. \\
CGP 45384 & $6.7 \pm 0.4$ & $14.3 \pm 1.5$ & N.D. \\
CGP 45385 & $2.3 \pm 0.4$ & $2.9 \pm 0.6$ & N.D. \\
ML1 & $4.2 \pm 0.6$ & $2.5 \pm 0.3$ & N.D. \\
ML2 & $1.3 \pm 0.4$ & N.D. & N.D. \\
ML3 & N.D. & N.D. & N.D. \\
ML4 & N.D. & N.D. & N.D. \\
ML5 & $8.7 \pm 1.6$ & $9.1 \pm 0.3$ & $14.0 \pm 1.4$ \\
ML6 & $2.4 \pm 0.2$ & $9.4 \pm 0.6$ & $7.2 \pm 0.4$ \\
ML7 & $0.9 \pm 0.1$ & N.D. & N.D. \\
MLa & $0.8 \pm 0.4$ & N.D. & N.D. \\
MLb & $4.2 \pm 0.8$ & N.D. & N.D. \\
MLc & $1.0 \pm 0.2$ & N.D. & N.D. \\
MLd & $1.2 \pm 0.2$ & N.D. & N.D. \\
\hline Other & $13.2 \pm 1.0$ & $22.5 \pm 3.6$ & $55.2 \pm 1.6$ \\
Recovery & $93.8 \pm 0.2$ & $90.0 \pm 0.4$ & $76.4 \pm 0.5$ \\
\hline are 6
\end{tabular}

Data are expressed as the mean values \pm S. E. for three animals. N.D. : Not detected.

Table X Composition of CGS 16949 and its metabolites in kidney after a 21 day period of daily oral administration of ${ }^{14}$ C-CGS 16949 A $1 \mathrm{mg} / \mathrm{kg}$ to non-fasted female rats

\begin{tabular}{lrcc}
\hline \hline \multirow{2}{*}{ CGS 16949 and } & \multicolumn{3}{c}{$\%$ of radioactivity in kidney } \\
\cline { 2 - 4 } its metabolites & \multicolumn{1}{c}{$2 \mathrm{hr}$} & $8 \mathrm{hr}$ & $24 \mathrm{hr}$ \\
\hline CGS 16949 & $53.5 \pm 0.5$ & $17.5 \pm 1.0$ & N.D. \\
CGP 45383 & $9.4 \pm 0.8$ & $8.0 \pm 1.0$ & N.D. \\
CGP 45384 & $5.1 \pm 0.4$ & $12.2 \pm 1.5$ & N.D. \\
CGP 45385 & $3.6 \pm 0.4$ & $10.0 \pm 1.9$ & N.D. \\
MK1 & $1.7 \pm 0.1$ & N.D. & N.D. \\
MK2 & N.D. & N.D. & N.D. \\
MK3 & $3.3 \pm 0.9$ & $8.6 \pm 0.5$ & $9.1 \pm 0.2$ \\
MK4 & N.D. & N.D. & N.D. \\
MKa & $1.8 \pm 0.5$ & N.D. & N.D. \\
Others & $11.4 \pm 0.6$ & $25.0 \pm 2.1$ & $54.4 \pm 1.4$ \\
Recovery & $89.9 \pm 0.8$ & $81.4 \pm 0.9$ & $63.5 \pm 1.2$ \\
\hline
\end{tabular}

Data are expressed as the mean values $\pm \mathrm{S}$. E. for three animals. N.D. : Not detected. 
At $24 \mathrm{hr}$, the relative amounts of ML5 and ML6 were $14.0 \%$ and $7.2 \%$ of radioactivity, respectively.

Compared with the data after single dosing ${ }^{2}$, the relative amount of unchanged CGS 16949 decreased.

\section{5) Metabolites in kidney}

The radioactivity concentration of CGS 16949 in the kidney at 2 hr after 21st dosing was 946 ng eq. of CGS $16949 / \mathrm{g}$, which accounted for $53.5 \%$ of radioactivity in the kidney (Table X). The ralative amounts of CGP 45383, CGP 45384 and CGP 45385 were 3.6 $9.4 \%$ of radioactivity in the kidney.

At 8 hr after 21st dosing, the radioactivity concentration of CGS 16949 decreased to 155 ng eq. of CGS $16949 / \mathrm{g}$, which accounted for $17.5 \%$ of radioactivity. The relative amounts of CGP 45383, CGP 45384 and CGP 45385 were $8.0 \sim 12.2 \%$ of radioactivity. MK3 accounted for $8.6 \%$ of radioactivity in kidney.

At 24hr, unknown metabolite MK3 was found as $9.1 \%$ of radioactivity in kidney.

Compared with the data after single dosing ${ }^{2}$, the relative amount of CGS 16949 decreased and that of MK3 increased after 21st dosing.

\section{DISCUSSION}

Larger variation of plasma concentration was found after 11th dosing in comparison with plasma concentration from 1st to 10th dosing (Fig. 2), but the reason is unclear. Since the plasma concentrations of radioactivity were almost the same at 15th, 17th, 19th and 20th dosing, it is suggested that the plasma concentration of radioactivity reaches a steady state after 15 th dosing. The administration time (15times) to reach the steady state in the plasma concentration is roughly in accordance with that the radioactivity concentrations in many tissues including plasma and blood were similar at the 7 th and 14th dosing (Table III), indicating that a steady state would be found by 15 th dosing.

The radioactivity concentration in the aorta did not reach the steady state and increased with dosing. Further the elimination of radioactivity from the aorta was slow and the radioactivity concentration in the aorta was $33 \%$ of the maximum at $672 \mathrm{hr}$ after the 21st administration. Pfaar et al. (internal report) reported that the uptake of radioactivity into the fibrous connective tissues (collagen and elastin) of blood vessels was found after repeated oral administration of ${ }^{14} \mathrm{C}-\mathrm{CGS} 16949 \mathrm{~A}$ to male rats. Referring that histidine can react with such aldimines by forming a covalent $\mathrm{C}-\mathrm{C}$ bond between the imidazoyl moiety of histidine and the aldimine ${ }^{3)}$, they suggested that a similar reaction with the imidazole moiety of ${ }^{14} \mathrm{C}-\mathrm{CGS} 16949 \mathrm{~A}$ may be responsible for the uptake of radioactivity in the walls of blood vessels. Therefore, remaining of radioactivity in the aorta (Table N) may be caused by the binding of the radioactivity with collagen and/or elastin.

The relative amounts of the metabolites in the liver and kidney after the 21st dosing were changed and the relative amount of unchanged CGS 16949 was decreased, compared with that after single dosing ${ }^{2}$. This might be due to the slower decline of metabolites compared with that of CGS 16949.

The urinary and fecal excretion of radioactivity reached almost a steady state after the 4 th dosing and the each excretion ratio was similar to that after single dosing ${ }^{2)}$. 
Compositions of CGS 16949 and its metabolites in urine after repeated dosing were similar to that of single dosing. After repeated dosing, some metabolites were found as several parcentage in fecal radioactivity, although those relative amounts were N.D. levels after single dosing. The increase of the relative amount of some metabolites might be the result of actualization based on the pile of very small amount of metabolite. Relevantly the relative amount of CGS 16949 decreased after repeated administration. Therefore, repeated administration might not affect the excretion of CGS 16949 and its metabolites.

Since the relative amount of CGS 16949 and its main metabolites in the urine, as the main route of excretion, did not change significantly, the metabolism of CGS 16949 after repeated administration would be similar to that after single dosing.

The metabolites, MP2, MU7, ML5 and MK3 found in the plasma, urine, liver and kidney, respectively, have the same retention time $(26 \mathrm{~min})$, indicating that these would be the identical compound.

\section{REFERENCES}

1) Schieweck, K., Bhatnagar, A.S. and Matter, A. : CG S 16949A, a New Nonsteroidal Aromatase Inhibitor: Effects on Hormone-dependent and indipendent Tumors in Vivo. Cancer research, $48: 834-838$ (1988).

2) Yamagami, S., Kawasaki, E., Egawa, A., Esumi, Y., Hori, K., Ishizaki, M., Honda, T. and Moriki, H. : Studies on the dispositin of fadrozole hydrochloride (CGS16949A) ( I ). Absorption, distribution, metabolism and excretion after a single oral administration to rats. Xenobio. Metabol. and Dispos., 8 : 1097-1127 (1993).

3) Yamauchi, M., London, R.E., Guenat, C., Hasimoto, F. and Mechanic, G.L. : Structure and formulation of a stable histidine-based trifunctional cross-link in skin collagen. J. Biol. Chem., 262: 11428-11434 (1987). 